\title{
Reply to Hall J: "Use of the Fluocinolone Acetonide Intravitreal Implant for the Treatment of Noninfectious Posterior Uveitis: 3-Year Results of a Randomized Clinical Trial in a Predominantly Asian Population"
}

\author{
Virender S. Sangwan, P. Andrew Pearson, Hemanth Paul, \\ Timothy L. Comstock
}

Baldo Scassellati Sforzolini

To view enhanced content go to www.ophthalmology-open.com Received: March 2, 2015 / Published online: March 21, 2015

(c) The Author(s) 2015. This article is published with open access at Springerlink.com

I read with interest Dr. Hall's letter. While the article titled "Use of the Fluocinolone Acetonide Intravitreal Implant for the Treatment of Noninfectious Posterior Uveitis (NIPU): 3-Year Results of a Randomized Clinical Trial in a Predominantly Asian Population" [1] clearly identified Retisert $^{\circledR}$ (fluocinolone acetonide intravitreal implant) $0.59 \mathrm{mg}$ as the marketed product used in the study, we appreciate Dr. Hall's concern that there may be some potential confusion regarding the features of Retisert compared with those of Iluvien ${ }^{\circledR}$ (fluocinolone acetonide intravitreal implant) $0.19 \mathrm{mg}$, as they both contain fluocinolone acetonide as the active ingredient, and we are in support of a letter outlining their differences [2].

However, we disagree with the promotional implication that Iluvien is an "improvement" over Retisert as there are no head-to-head clinical trials comparing these two products to merit that claim. Indeed, in addition to the approval for treatment of chronic non-infectious posterior uveitis, clinical studies have shown Retisert to be

B. Scassellati Sforzolini $(\bowtie)$

Eye Care, Valeant Pharmaceuticals, Bridgewater, NJ, USA

e-mail: Baldo.Sforzolini@bausch.com effective in reducing diabetic macular edema (DME) and improving visual acuity in patients with DME [3]. Retisert has also shown efficacy in the management of macular edema secondary to retinal vein occlusion in small studies $[4,5]$. However, as Dr. Hall correctly stated, Retisert is not approved either in the US or in Europe for these latter indications.

Baldo Scassellati Sforzolini, MD, PhD, MBA

Vice President Development, Eye Care, Valeant Pharmaceuticals

Bridgewater, NJ, USA

Baldo.Sforzolini@bausch.com

\section{OPEN ACCESS}

This article is distributed under the terms of the Creative Commons Attribution Noncommercial License which permits any noncommercial use, distribution, and reproduction in any medium, provided the original author(s) and the source are credited.

\section{REFERENCES}

1. Sangwan VS, Pearson PA, Paul H, Comstock TL. Use of the fluocinolone acetonide intravitreal implant for 
the treatment of noninfectious posterior uveitis: 3 -year results of a randomized clinical trial in a predominantly Asian population. Opthalmol Ther. doi:10.1007/s40123-014-0027-6.

2. Hall J. Comment on: Use of the fluocinolone acetonide intravitreal implant for the treatment of noninfectious posterior uveitis: 3-year results of a randomized clinical trial in a predominantly Asian population. Ophthalmol Ther. 2014. doi:10.1007/ s40123-015-0029-z.

3. Pearson PA, Comstock TL, Ip M, et al. Fluocinolone acetonide intravitreal implant for diabetic macular edema: a 3-year multicenter, randomized, controlled clinical trial. Ophthalmology. 2011;118(8):1580-7.
4. Ramchandran RS, Fekrat S, Stinnett SS, Jaffe GJ. Fluocinolone acetonide sustained drug delivery device for chronic central retinal vein occlusion: 12-month results. Am J Ophthalmol. 2008;146:285-91.

5. Jain N, Stinnett SS, Jaffe GJ. Prospective study of a fluocinolone acetonide implant for chronic macular edema from central retinal vein occlusion: thirty-sixmonth results. Ophthalmology. 2012;119:132-7. 